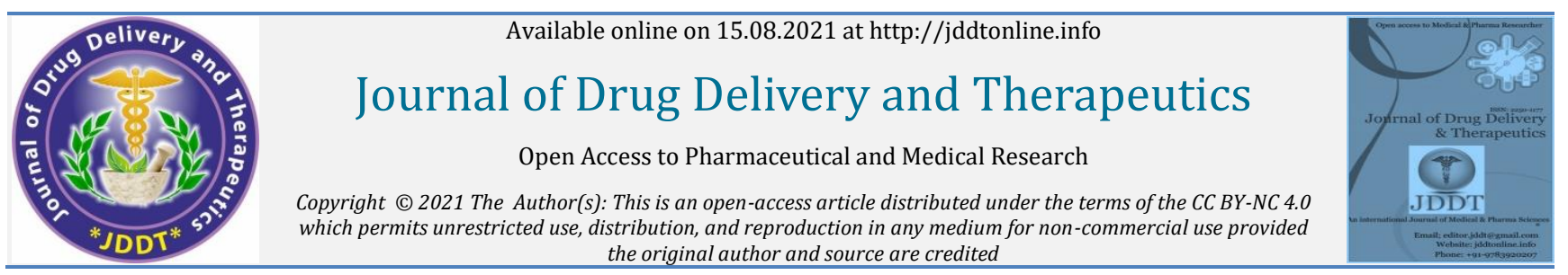

Open Access Full Text Article the original author and source are credited
and

\title{
Pharmacological evaluation for Anti-Anxiety and CNS depressant activity of hydro-alcoholic leaves extract of Pongamia pinnata
}

\author{
Panda Jagannath* (D), Samantaray Biswajit, Pattnaik Gurudutta \\ School of Pharmacy and Life Sciences, Centurion University of Technology and Management, Bhubaneswar, Odisha, India
}

Article Info:

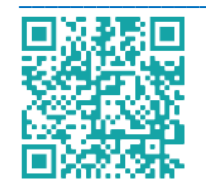

Article History:

Received 08 June 2021

Reviewed 13 July 2021

Accepted 20 July 2021

Published 15 August 2021

\section{Cite this article as:}

Panda J, Samantaray B, Pattnaik G, Pharmacological evaluation for Anti-Anxiety and CNS depressant activity of hydro-alcoholic leaves extract of Pongamia pinnata, Journal of Drug Delivery and Therapeutics. 2021; 11(4-S):22-25

DOI: http://dx.doi.org/10.22270/jddt.v11i4-S.4962

\section{Abstract}

The aim of this study was to assess the anti-anxiety and CNS depressant properties of hydroalcoholic extract of Pongamia pinnata leaves (HALEPP). Standard methods were used to screen the HALEPP's phytochemicals, which showed that the extract contains Flavones, alkaloids, glycosides, proteins and amino acids, gum and mucilage as well as flavonoids, saponins, and steroid hormones. Even at the dose level of $1000 \mathrm{mg} / \mathrm{kg}$ body weight, the HALEPP showed no signs of toxicity or mortality in the acute toxicity report. The anti-anxiety behaviour of was studied using light and dark model methods in rats. The CNS depressant action was studied using the extract and actophotometer (Rolex) in rats. The research group (HALEPP $200 \mathrm{gm} / \mathrm{kg}$ treated) animals displayed strong anti-anxiety and CNS depressant behaviour similar to the control group (diazepam treated) animals in the current study. The study's findings suggest that the hydro-alcoholic Pongamia pinnata leaf extract has strong anti-anxiety and CNS depressant properties.

Keywords: Pongamia pinnata, Anti-Anxiety \& CNS depressant

*Address for Correspondence:

Panda Jagannath, School of Pharmacy and Life Sciences, Centurion University of Technology and Management, Bhubaneswar, Odisha, India

ORCID ID: https://orcid.org/0000-0002-6023-244X

\section{INTRODUCTION:}

Stress is a natural occurrence that affects everyone at some point in their lives. ${ }^{1}$ When stress becomes excessive, it is detrimental to the body and must be addressed ${ }^{2}$. Stress plays a role in the pathogenesis of a number of diseases, including diabetes mellitus, male impotence, congestive dysfunction, peptic ulcer disease, hypertension, and ulcerative colitis. A together to produce an uncomfortable sensation that is often associated with unease, anticipation, anxiety, or concern. 3,4 Anxiety is a mood disorder that can strike without warning and without a specific cause. As a result, it is distinct from terror, which happens when a threat is perceived. Furthermore, anxiety is the product of risks that are thought to be uncontrollable or imminent, while fear is linked to complex behaviors such as escape and avoidance. Defensive actions, autonomic reflexes, arousal and alertness, corticosteroid secretion, and negative emotions are all part of the natural fear response to threatening stimuli. These responses occur in anxiety states in an anticipatory way, regardless of external events. ${ }^{5}$ The line between a 'pathological' and a 'natural' condition of anxiety is blurry, but it denotes the stage at which the symptoms obstruct normal productive activities. Anxiolytic drugs were once among the most commonly used drugs in general practice, despite (or perhaps because of) this hazy distinction. They've feeling of fear, confusion, or tension stemming from the anticipation of an imagined or unreal treat is referred to as human anxiety.1,2 It's an uncomfortable emotional state associated with uneasiness, anxiety, and worry or fear about a specific potential danger. ${ }^{2}$ Anxiety is a psychological and physiological condition that includes cognitive, somatic, emotional, and behavioral aspects. These elements work

lost favour as the unpredictability of their benefits and the certainty of their risks became clear. ${ }^{6}$

Anxiety affects one-eighth of the world's population and has been a major focus of psychopharmacology studies in the last decade. The most widely prescribed medication for anxiety is benzodiazepines (BZDs), which are the most common type of compounds used in anxiety. However, the fact that BZDs have a small safety margin has led many researchers to test new compounds in the hopes of finding alternative anxiolytic drugs with less undesirable side effects. 7,8

Central nervous system depression, also known as CNS depression, is a neurological depression of the central nervous system that causes slowed breathing, slowed heart rate, and loss of consciousness, which may lead to coma or death. Depressant medications like alcohol, antidepressants, barbiturates, benzodiazepines, general anaesthetics, and 
anticonvulsants like valproate used to treat epilepsy are the most common causes of CNS depression. ${ }^{4}$

Physiological central nervous system depression, general or local anaesthesia, skeletal muscle relaxation, or anticonvulsant movements are all examples of Central Nervous System activities. Many depressants and anaesthetics work on the central nervous system by increasing the activity of a neurotransmitter called gammaaminobutyric acid (GABA), though other targets such as the $\mathrm{N}$-methyl D-aspartate (NMDA) receptor, opioid receptor, and CB1 cannabinoid receptor may also be essential, depending on the medication. Skeletal muscle relaxants decrease muscle tone by acting peripherally at the neuromuscular junction or in the cerebrospinal axis. ${ }^{8}$ CNS depressants and the CNS distress they cause are pharmacologically known as major tranquillizers like chlorpromazine. ${ }^{7}$

Plant Profile: The Pongamia pinnata, also known as 'Karanja,' has been used to treat a variety of diseases in various traditional medicine systems. Pongamia pinnata is a member of the fabaceae family. It's a medium-sized evergreen tree with a short bole and a spreading crown. $P$. pinnata plant is used as an anti-inflammatory, antiplasmodial, anti-nociceptive, anti-hyperglycaemic, anti-lipid oxidative, anti-diarrhoeal, anti-ulcer, anti-hyper ammonic, and antioxidant in conventional medicine systems. ${ }^{21}$

\section{MATERIALS \& METHODS:}

Plant: Pongamia pinnata leaves were collected from its natural habitat in nearby Badaghan village, Baliguda, Kandhamal district of Orissa in January 2021. The leaves were washed and dried before being used. It was dried in the shade to prevent the volatile oil from degrading. A total of 75 grams of powder is subjected to a 1:1 maceration process with water and ethanol. The extracts were powdered after drying. Phytochemical and pharmacological activity tests were performed on the extracts.

Animal: Wistar albino rats weighing 180-200 gm were used for pharmacological screening and young female albino mice weighing 22-28 gm were used for acute toxicity studies. All of the animals were obtained from the S.P.L.S.,C.U.T.M. Bhubaneswar animal house and housed in polypropylene cages. Animals were held in a 12:12 hour light:dark period with a regulated room temperature $\left(222^{\circ} \mathrm{C}\right)$ and humidity $\left(555^{\circ} \mathrm{C}\right)$. The animals were given an ad libitum diet of laboratory food made in-house and pure drinking water.

The thesis received ethical approval from the S.P.L.S,C.U.T.M Bhubaneswar Institutional Animal Ethics Committee. The experimental work was carried out from January to April 2021, following the requisite approval. The animal experiments were carried out in accordance with the ethical guidelines set out by the Committee for the Control and Supervision of Experiments on Animals.

Hydro alcoholic extraction: Hydro alcoholic (1:1) extract was used to remove the powdered leaves of Pongamia pinnata. The extracts were powdered after drying. We tabulated the extractive qualities, colour, and consistency.
Phytochemical screening: To identity of various Phytoconstituents in a hydro-alcoholic extract of Pongamia pinnata leaves (HALEPP) was investigated using qualitative phytochemical analysis.

Acute toxicity studies: The HALEPP underwent an acute oral toxicity trial in accordance with OECD guidelines. The young female albino mice were divided into five classes, each with six mice. The animals in the control group were given 5 $\mathrm{ml} / \mathrm{kg}$ of distilled water orally. The other five research group animals were given oral doses of HALEPP of 100,500, and $1000 \mathrm{mg} / \mathrm{kg}$, respectively. The animals were monitored continuously for the first 4 hours after receiving the medications, then on an as-needed basis for the next 24 hours, with any mortality reported at the end of 72 hours. Behavioral changes, somatomotor activity, tremors, convulsions, tonic extension, strub tail, muscle spasm, loss of righting reflex, ataxia, sedation, hypnosis, lacrimation, diarrhoea, salivation, writhing, changes in skin, fur, eyes, mucous membranes, and other findings were also reported.

Evaluation of anti-anxiety and CNS depressant activities: A total of twenty-four wistar albino rats were split into three classes. Then, for 5 days prior to the analysis, drugs were given to the various groups of animals via oral route according to the schedule shown in table 1 . The animals were brought for the pharmacological analysis 30 minutes after receiving the medication on the fifth day.

Table 1: Drug administration to different groups of animals:

\begin{tabular}{|l|l|l|l|}
\hline Group & Drug & Dose $(\mathrm{mg} / \mathrm{Kg})$ & Nature \\
\hline 1. & Distilled Water & $10 \mathrm{ml} / \mathrm{Kg}$ & Control \\
\hline 2. & Diazepam & 2 & Standard \\
\hline 3. & HALEPP-200 & 200 & Test \\
\hline
\end{tabular}

Light and dark model test: The anti-anxiety activity is studied using a light and dark model test. For 5 minutes, each animal was put in the light and dark apparatus, and parameters such as the number of entries into each chamber and the average time spent in each chamber were recorded. 19,20

Actophotometer Test: Animals' spontaneous motor activity will increase or decrease if a drug increases or decreases CNS activity. This is how the actophotometer is produced. An actophotometer, which is primarily used to research the drug's C.N.S depressant property, can easily assess locomotor activity. ${ }^{12}$

\section{RESULTS:}

*Percentage of yield $(w / w)$ and colour of extracts: To obtain the crude extract, the Pongamia pinnata extract was purified and then condensed by distilling off the solvent. The different extracts' extractive values, colours, and consistency are mentioned below.

Table 2: Percentage of yield $(w / w)$ and colour of extracts:

\begin{tabular}{|l|l|l|l|l|}
\hline S.N. & Method of Extraction & \% yield(w/w) & Colour & Consistency \\
\hline 1. & Hydro-Alcoholic Extraction(1:1) & $8.2 \%$ & Brown & Greasy mass \\
\hline
\end{tabular}


Phytochemical studies: HALEPP was found to contain alkaloids, phenolics, glycosides, saponins, and steroid in a preliminary qualitative phytochemical screening (table-3).

Table 3: Phytochemical Study of hydro-alcoholic extract of leaves of Pongamia pinnata:

\begin{tabular}{|l|l|c|}
\hline S. N. & Phytoconstituents & HALEPP \\
\hline 1 & Alkaloid & + \\
\hline 2 & Carbohydrate & - \\
\hline 3 & Protein \& Amino acid & + \\
\hline 4 & Gum and Mucilage & + \\
\hline 5 & Triterpinoids & - \\
\hline 6 & Glycoside & + \\
\hline 7 & Tannins & + \\
\hline 8 & Saponins & + \\
\hline 9 & Flavones \& Flavonoids & + \\
\hline 10 & Steroids \& Sterols & + \\
\hline
\end{tabular}

(+) Sign indicates Present and (-) indicates Absent

Pharmacological Study:

Acute toxicity studies:

The results of acute oral toxicity study of HALEPP are tabulated below.

\begin{tabular}{|l|l|l|l|l|}
\hline Treatment & Dose $(\mathrm{mg} / \mathrm{kg})$ & No. of Mice & No. of Death & signs of toxicity \\
\hline Control (Distilled water) & $10 \mathrm{ml} / \mathrm{kg}$ & 5 & 0 & - \\
\hline \multirow{3}{*}{ HALEPP } & 100 & 5 & 0 & - \\
\cline { 2 - 5 } & 500 & 5 & 0 & - \\
\cline { 2 - 5 } & 1000 & 5 & 0 & - \\
\hline
\end{tabular}

Pharmacological evaluation of CNS depressant and anti-anxiety activity: The outcomes of various pharmacological screening procedures the results of the HALEPP effect analysis are listed below.

\section{Actophotometer method:}

CNS depressant effect of HALEPP on rats by actophotometer apparatus:

\begin{tabular}{|l|l|l|l|l|}
\hline Group & Treatment & Dose $\mathbf{( m g / k g )}$ & Locomotor activity & \% Inhibition \\
\hline Group-1 & Distilled water & $10 \mathrm{ml} / \mathrm{kg}$ & $222.66 \pm 3.589$ & - \\
\hline Group-2 & Diazepam & 0.5 & $71.88 \pm 0.953$ & 65.21 \\
\hline Group-3 & HALEPP -200 & 200 & $86.33 \pm 8.265$ & 59.23 \\
\hline
\end{tabular}

\section{2) Light and Dark Model:}

Anxiolytic effect of HALEPP on rats by using light and dark model:

\begin{tabular}{|l|l|l|l|l|l|}
\hline Group & Treatment & $\begin{array}{l}\text { Dose } \\
(\mathbf{m g} / \mathbf{k g})\end{array}$ & $\begin{array}{l}\text { No of entry in to light } \\
\text { chamber }\end{array}$ & $\begin{array}{l}\text { Time spent (s) in } \\
\text { light chamber }\end{array}$ & $\begin{array}{l}\text { Time spent (s) in } \\
\text { dark chamber } \\
\text { chamber }\end{array}$ \\
\hline Group-1 & Distilled water & $10 \mathrm{ml} / \mathrm{kg}$ & $2.36 \pm 0.348$ & $23 \pm 0.936$ & $275 \pm 1.044$ \\
\hline Group-2 & Diazepam & 1 & $5.89 \pm 0.628$ & $206 \pm 1.756$ & $93 \pm 0.977$ \\
\hline Group-3 & HALEPP -200 & 200 & $5.45 \pm 0.624$ & $184 \pm 0.951$ & $115 \pm 1.285$ \\
\hline
\end{tabular}




\section{CONCLUSIONS:}

In Dark Light model test, both the normal group (Diazepam treated) and the test group (HALEPP-200 treated) animals showed a significant improvement in time spent in the bright chamber and rearing behaviour as compared to the control group animals. The hydro-alcoholic extract of leaves of Pongamia pinnata plants appears to have major anxiolytic effects based on behavioural changes. The hydro-alcoholic extracts of Pongamia pinnata have also been shown to have CNS depressant activity, as evidenced by the fact that they significantly decreased locomotor activity in an actophotometer. ${ }^{16 ;} 17$

The above results indicate that a $200 \mathrm{mg} / \mathrm{kg}$ hydro-alcoholic extract of Pongamia pinnata leaves has significant antianxiety and CNS depressant activity.

\section{REFERENCES:}

1. Tripathy KD. Essentials of Medical Pharmacology. 6thed. New Delhi: Jaypee Brothers Medical Publishers (P) Ltd; 2008.

2. Rang HP, Dale MM, Ritter JM, Moore PK. Pharmacology. 6th ed. Philadelphia: Churchill Livingstone; 2007.

3. Li L, Li X, Shi C, Deng Z, Fu H, Proksch P. Five flavonoids from the stems of a mangrove plant, Pongamiapinnata. Phytochem. 2006; 67:1347-52. https://doi.org/10.1016/j.phytochem.2006.05.016

4. Shameel S, Usmanghani K, Ali MS. Chemical constituents from seeds of Pongamia pinnata (L.) Pierre. Pak J Pharm Sci. 1996; 9: $11-20$

5. Tanaka T, Iinuma M, Yuki K. Flavonoids in root bark of Pongamia pinnata. Phytochem. 1992; 31:993-8. https://doi.org/10.1016/0031-9422(92)80055-J

6. Reddy S, Reddy C, Murthy KN, Raju VS. Traditional medicinal plants in Seshachalam hills, Andhra Pradesh, India. J of Med plants Res. 2009; 3(5):408-12.

7. Kirtikar KR, Basu BD. Indian Medicinal plants. Vol. I, 2nd ed. Dehradun: International Book Distributors; 1998. p. 588-596.

8. Srinivasan K, Muruganandan S, Lal J. Evaluation of antiinflammatory Research Journal of Pharmacy and Life Sciences: Volume 1, Issue 3; September - December, 2020: Page 98 - 108 107 activity of Pongamia pinnata leaves in rats. J Ethnopharmacol. 2001; 78:151- 7. https://doi.org/10.1016/S0378-8741(01)00333-6

9. Simonsen HT, Nordskjold JB, Smitt UW. In vitro screening of Indian Medicinal Plants for antiplasmodial activity. J
Ethnopharmacol. 2001; 74:195-204.

https://doi.org/10.1016/S0378-8741(00)00369-X

10. Essa MM, Subramanian P. Pongamia pinnata modulates oxidant and antioxidant imbalance in ammonium chloride induced hyper ammonem. FundamlClinPharmacol. 2006; 20:299-303. https://doi.org/10.1111/j.1472-8206.2006.00410.x

11. Chopade VV, Tankar AN, Pande VV, Tekade AR, Gowekar NM, Bhandari SR, Khandake SN. Pongamiapinnata: Phytochemical constituents, traditional uses and pharmacological properties: A review. 2008; 2(2):72- 75. https://doi.org/10.4103/09738258.41173

12. Brijesh S, Daswani PG, Tetali P. Studies on Pongamia pinnat (L.) Pierre leaves: Understanding the mechanism(s) of action in infectious diarrhea. J Zhejiang Univ Sci. 2006; 7:665-74. https://doi.org/10.1631/jzus.2006.B0665

13. Prabha T, Dora M, Priyambada S. Evaluation of Pongamia pinnata root Extract on gastric ulcers and mucosal offensive and defensive factors in rats. Indian J Exp Biol. 2003; 41:304-10.

14. Punitha R, Manoharan S. Antihyperglycemic and antilipid peroxidative effects of Pongamia pinnata (linn.) Pierre flowers in alloxan induced diabetic. J EthonPharmacol. 2006; 105: 39-46. https://doi.org/10.1016/j.jep.2005.09.037

15. Panigrahi G, Panda C, Patra A. Extract of Sesbaniagrandiflora ameliorates hyperglycemia in high fat diet-streptozotocin induced experimental diabetes mellitus. Scientifica. 2016; 1-10. https://doi.org/10.1155/2016/4083568

16. Kokate CK. Practical Pharmacognosy, 4 th ed. NewDelhi: VallabhPrakashan; 1994. p. 107-111. 11.

17. Khandelwal KR. Practical Pharmacognosy Techniques and Experiments, 11th ed. Pune: NiraliPrakashan; 2000. p. 149-156.

18. Ghosh MN. Fundamentals of Experimental Pharmacology. 3rd ed. Kolkata: Hilton \& Company; 2005. p. 175-179, 192-197.

19. Panigrahi G, Patra A. Experimental Pharmacology- I, II and III (Bridges the Gap Between Animal Models and Computer Simulation Models). 1st ed. Pune: Nirali Prakashan; 2019.

20. Vogel HG. Drug discovery and evaluation: Pharmacological Assays. Vol II, 3rd ed. New York: SpringerVerlag Berlin Heidelberg; 2008. p. 1103-106. https://doi.org/10.1007/978-3540-70995-4

21. Rai D, Bhatia G, Patil G, Pal R, Singh S and Singh HK. Adaptogenic effect of Bacopa monniera (Bramhi). PharmacolBiochemBehav. 2003; 75:823-30. https://doi.org/10.1016/S00913057(03)00156-4 